\title{
Internal versus external complexity: how organizations react
}

\author{
$\underline{\text { Bizhan Jamshidnezhad }}$ \\ School of Business and Management, Asia Pacific International College \\ 55 Regent St., Chippendale, 2008, NSW \\ E-mail:bizhan@apicollege.edu.au
}

\begin{abstract}
This paper investigates the effects of environmental complexity on organizational performance by means of computational modeling. There are few works that prepare a bottom-up, mechanism-based account of organization-environment interactions. Rather, a lot of top-down, statistical models have been developed which fall short of explaining how an organization can handle uncertainties. The theoretical foundation of this paper is based on the concept of learning, which is a running thread linking organization science with the agent-based modeling paradigm. The definition of environmental complexity is based on Shannon's famous information entropy which represents a good conceptualization of complexity. The definition contains appropriately all facets of environmental uncertainty including degree of uncertainty, number of decision elements, and interdependence or interrelatedness among decision elements. In this paper, the process conception of learning is considered, because it is consistent with behavioral theory of organizational learning and can be modeled as a learning algorithm. Organizational learning is modeled as a Reinforcement Learning (RL) algorithm that operates as a trial-and-error search with delayed reward. The appropriateness of RL comes from the fact that the overall objective of managers is to align organizations towards environmental requirements and thus the environment feedback plays a key role in the decision making process within any organization. Among various conceptualizations of organizations, they are viewed problem-solving entities in this paper. The question considered is how environmental complexity affects organizational performance.

To examine the effects of environmental complexity, an organization is exposed to different levels of environmental complexity, represented as decision rules. The requirements to accommodate environmental complexity have some counterintuitive effects on productivity. The results of the model show that the complexity of environment requirements has positive effects on organizational performance. In other words, if the organization can learn from the complexity of the environment, it can improve its performance. The computational model developed can be used to investigate other questions like the effects of internal complexity or organizational memory on performance.
\end{abstract}

Keywords: Agent-based simulation, multi-agent systems, complexity, learning 


\section{INTRODUCTION}

Organizations are artificial entities that depend on their environments in a contingent way (Simon 1996). They are surrounded by physical, technological, cultural, and social environments that tended to be overlooked or underestimated by early analysts of organizations. Recently, the importance of organizationenvironment linkages has drawn the attention of organization scholars, because every organization is dependent on its environment for survival (Scott 1998). As Godwyn and Gittel (2012) cite, "organizations succeed to the extent that their structures match the requirements of their environments". In Simon's (1996) terms, environments act like a mold and affect organizations as artifacts. It is difficult to define the concept of fitness to environment for organizations, but in the real world the match between organizational strategic orientation and that which the environment requires is a measure of fitness (Sastry 1997). Dynamics of business environments give rise to some changes in the ways organizations are formed (Siggelkow and Rivkin 2005) as well as their operations (Lin and Carley 2003). This is called adaptation (or fitness) to changes.

According to contingency theory, there is a direct link between the environmental uncertainties and the internal structure of an organization for adaptation in that "the greater the uncertainty of the task, the greater the amount of information that has to be processed between decision makers during its execution" (Galbraith 1973: 4). The amount of information needed to ensure effective performance of organizations is represented as $f(u, n, c)$, where $u$ is the degree of uncertainty concerning the task requirements such as resources needed, time to complete etc; $\mathrm{n}$ is the number of elements relevant for decision making; and $\mathrm{c}$ is interdependence and interrelatedness among the elements (Godwyn and Gittell 2012). The concept of environmental uncertainty is modeled by taking into account different aspects of uncertainty as outlined above that will be discussed later.

The paper is intended to act as a computational laboratory for investigating the interaction between organizations and their environments. A learning conception of organization-environment interactions within the framework of complex adaptive systems is presented in this research. The question is how organizations react to the external sources of complexity compared to the internal ones. There are two meanings of learning: (i) improvement in outcomes (e.g. learning curves in economics) (ii) a particular process of reacting to information involving: beginning with the taking of an action, monitoring the outcome, and interpretation and then modification of the propensity to repeat the action which has the elements of intelligence (March 2008). In this paper, the process conception of learning is considered, because it is consistent with behavioral theory of organizational learning and can be modeled as a reinforcement learning algorithm. The environmental complexity is defined based on Shannon's famous information entropy which is claimed to be a thorough conception of complexity, because it contains appropriately all facets of environmental uncertainty including degree of uncertainty, number of decision elements, and interdependence or interrelatedness among decision elements, already been cited from Godwyn and Gittell (2012). In the next section, the structure of the developed model is explained followed by some results and discussions.

\section{THE COMPUTATIONAL MODEL}

As a fusion of learning concepts in organization science and multi-agent systems, the developed model is founded on the behavioral approach to study the firm (Cyert and March 1963; March 2008). The process conception of learning is the logic behind the reinforcement learning (RL) algorithm developed that is explained later.

In Figure 1, the developed model is depicted. The organization, hereinafter called organization, is comprised of two simple processes, each containing two roles connected in a simple network. There are four types of agents, each with different problem solving capabilities. The initial layout seen in the figure is just an example as the computer program randomly assigns agents to the roles during initialization. The director of organization, hereinafter called $C E O$, is responsible for improving organization. The environment consists of an agent, hereinafter called environment, challenging organization by generating random problems. The objects generated by environment are problems comprised of a string of bits, representing environment's requirements. Accuracy of answers is a measure of effectiveness, while total processing time represents efficiency of organization. Through solving different problems, $C E O$ and analysts agents learn how to improve their performance, respectively. $C E O$ has another RL algorithm in order for improving organization as a whole by moving agents among roles. As Carley (2000) explains changes made in the design of organizations are actions for learning, therefore with changing positions (roles) of agents, CEO learns how to improve organizational performance. 
The dynamics of simulation is as follows: (1) environment generates random problems and sends them to organization; (2) $C E O$ collects a problem and distributes it in the process A. The agent at role one starts solving the problem; (3) each agent receives the problem and depending on its role looks at certain bits to provide the solution from its memory and sends the solution to its successor. The duration of problem solving depends on the number of bits each agent encounters; (4) CEO provides the overall answer and passes it to environment; (5) according to a decision making rule, environment finds the current answer and updates $C E O$ and the other agents; (6) with a fixed frequency, CEO tries to make some changes in organization (based on a $\mathrm{RL}$ algorithm) to improve productivity (i.e. the ratio of accuracy of answers to total time spent).

Problems are classification choice tasks comprised of seven ternary variables $\mathrm{X}_{0}, \mathrm{X}_{1}, \mathrm{X}_{2}, \mathrm{X}_{3}, \mathrm{X}_{4}, \mathrm{X}_{5}, \mathrm{X}_{6}$; each can take one or two or three as its value with equal probability. The size of problems can be selected more than seven but it would increase the simulation time. The solution is "one" or "two" or "three" depending on the applied decision rule and cut-off values. The problem generation time is set at first and then is accumulated when a problem is processed at each role and pass through the network. The transfer time between agents is fixed at two simulation time units, called ticks. The difference between the generation time and the final time is a measure of efficiency. The performance measure defined here seems to be an appropriate measure because "the ratio of results achieved to resources consumed, is an appropriate and fundamental criterion for all of organizational decisions" (Simon 1997: 277). Not every agent has access to all bits of a problem due to division of work in an organization. The assignment of problem bits is shown at Table 1. This allocation scheme, representing the process approach in organizations, is kept constant for all experiments.

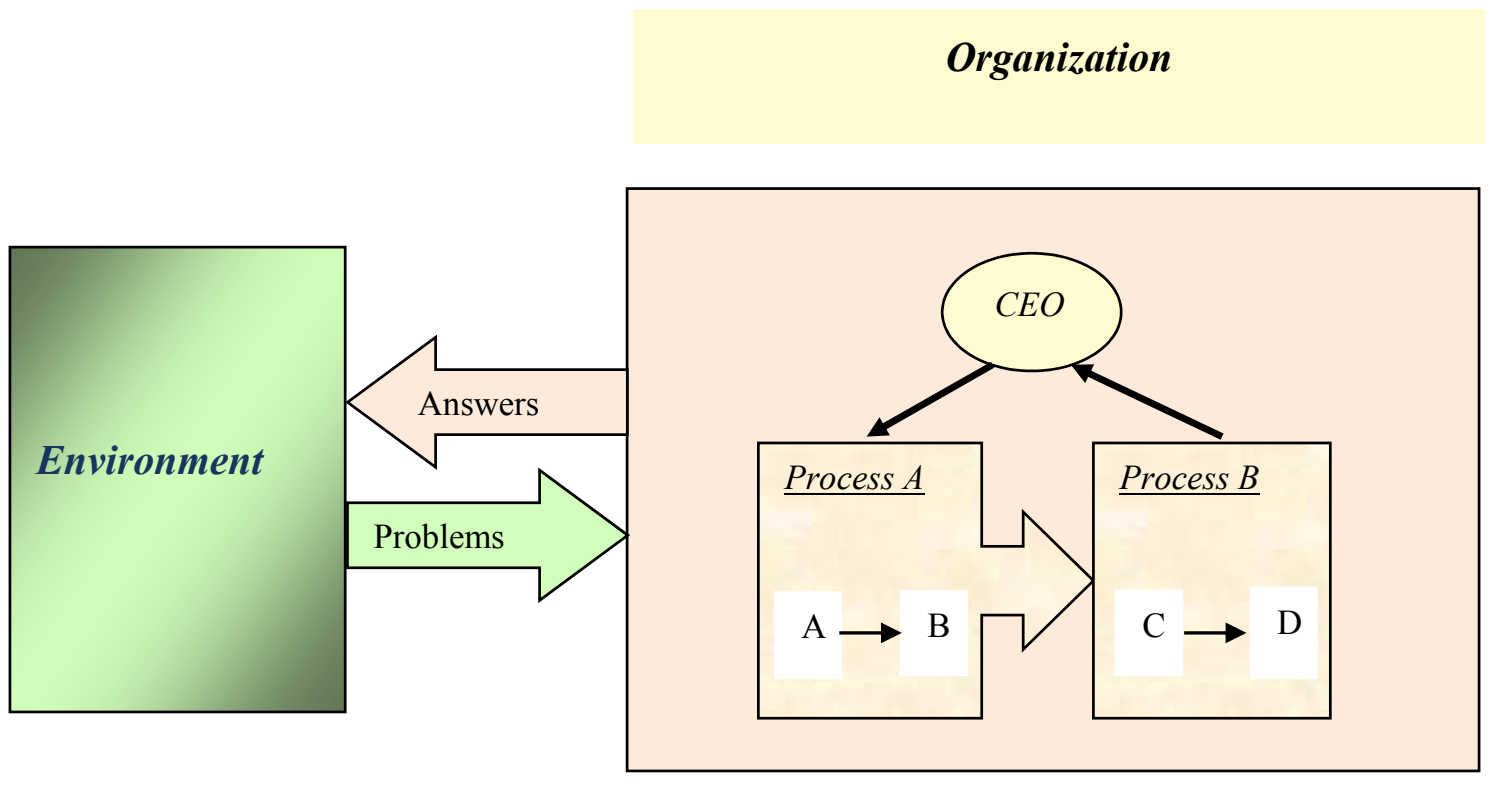

Figure 1. The structure of the multi agent model.

Organizational learning is modeled as a $\mathrm{RL}$ algorithm that operates based on a trial-and-error search and delayed reward. The appropriateness of RL comes from the fact that the overall objective of managers is to align organizations towards environmental requirements and thus the environment feedback plays a key role in the decision making process within any organization. $C E O$ tries to improve organization by modifying processes $\mathrm{A}$ and $\mathrm{B}$, where it changes the agent roles within and between these processes. The list of its actions is presented in Table 2. For instance, assume the layout of a simulation run is DBCA, meaning agent $\mathrm{D}$ at role one; agent $\mathrm{B}$ at role two; agent $\mathrm{C}$ at role three; and agent $\mathrm{A}$ at role four. By taking action 3 for example, CEO changes the layout of organization to DCBA. The consequence of each action (the reward) appears in the form of a rise or decline of average productivity, incremented by the following equation:

$$
\overline{\mathrm{r}_{\mathrm{t}+1}}=\overline{\mathrm{r}_{\mathrm{t}}}+\alpha\left[\mathrm{r}_{\mathrm{t}}-\overline{\mathrm{r}}_{\mathrm{t}}\right]
$$

where $\alpha$ is step-size parameter and $r_{t}$ is the productivity level of current run. Each action has a numeric preference level $\left(p_{t}(a)\right)$, incremented in each decision making stage according to the following equation: 


$$
\mathrm{p}_{\mathrm{t}+1}(\mathrm{a})=\mathrm{p}_{\mathrm{t}}(\mathrm{a})+\beta\left[\mathrm{r}_{\mathrm{t}}-\overline{\mathrm{r}_{\mathrm{t}}}\right]
$$

where $\beta$ is another step-size parameter. The preference of selecting successful actions rises gradually, which in turn increases the probability of their own selection according to the Gibbs distribution:

$$
\operatorname{Pr}\left\{\mathrm{a}_{\mathrm{t}}=\mathrm{a}\right\}=\frac{\mathrm{e}^{\mathrm{p}_{\mathrm{t}}(\mathrm{a})}}{\sum_{\mathrm{b}^{\mathrm{n}}=1}^{\mathrm{e}^{\mathrm{p}_{\mathrm{t}}}}}
$$

The default parameters of the simulation are shown in Table 3. These show agent A processes data quickest but has a poor 'memory' for the consequences of past decisions, in contrast to agent D who is slow at decisions making but has a perfect memory. Cut-off values determine the correct answers of each problem. For all scenarios, they are set so that the probability of correct answers being "one", "two", or "three" be equal to 0.33 . This guarantees that by changing decision rules, indifference of environment agent is maintained. For instance, the probability distribution of Linear decision rule is:

$$
\begin{gathered}
\mathrm{Y}_{\text {Linear }}=\sum_{\mathrm{i}=0}^{6} \mathrm{X}_{\mathrm{i}} \\
\operatorname{Pr}\left(\mathrm{Y}_{\text {Linear }}=\mathrm{k}_{1}+2 \mathrm{k}_{2}+3 \mathrm{k}_{3}\right)=\frac{7 !}{\mathrm{k}_{1} ! \mathrm{k}_{2} ! \mathrm{k}_{3} !}\left(\frac{1}{3}\right)^{7}
\end{gathered}
$$

where $k_{1}, k_{2}$, and $k_{3}$ represent the number of "one"s, "two"s, and "three"s in the problem bits. Therefore the lower cut-off can be calculated as follows:

$$
\operatorname{Pr}\left\{Y_{\text {Linear }} \leq \text { Lower cut-off }\right\}=\frac{1}{3} \stackrel{\text { yields }}{\longrightarrow} \text { Lower cut-off }=13
$$

The upper cut-off value for Linear decision rule is calculated in the same way. For other decision rules, the cut-off value requires to be modified, because their probability function is different. The specifications of some arbitrary decision rules tested in this research (including entropy and cut-off values) are shown in Table 4. As another example, cut-off values of Nonlinear rule are calculated here:

$$
\begin{gathered}
\operatorname{Pr}\left(\mathrm{Y}_{\text {Nonlinear }}=1^{\mathrm{k}_{1}} 2^{\mathrm{k}_{2}} 3^{\mathrm{k}_{3}}\right)=\frac{7 !}{\mathrm{k}_{1} ! \mathrm{k}_{2} ! \mathrm{k}_{3} !}\left(\frac{1}{3}\right)^{7} \\
\operatorname{Pr}\left\{\mathrm{Y}_{\text {Nonlinear }} \leq \text { Lower cut-off }\right\}=\frac{1}{3} \rightarrow \text { Lower cut-off }=36
\end{gathered}
$$

Table 1. Problem decomposition structure.

Table 2. CEO actions used for RL.

\begin{tabular}{|c|c|}
\hline Role 1 & $\mathrm{x}_{0}, \mathrm{x}_{1}, \mathrm{x}_{2}$ \\
\hline Role 2 & $\mathrm{x}_{5}$, output of Role 1 \\
\hline Role 3 & $\mathrm{x}_{3}, \mathrm{x}_{4}$, output of Role 2 \\
\hline Role 4 & $\mathrm{x}_{6}$, output of Role 3 \\
\hline CEO & output of Role 2, output of Role 4 \\
\hline
\end{tabular}

\begin{tabular}{|c|c|}
\hline Action & Description \\
\hline 1 & Swap agents at role 1 and 2. \\
\hline 2 & Swap agents at role 3 and 4. \\
\hline 3 & Swap agents at role 2 and 3. \\
\hline 4 & Swap agents at role 1 and 4. \\
\hline 5 & Swap agents at role 2 and 4. \\
\hline 6 & Swap agents at role 1 and 3. \\
\hline 7 & No change \\
\hline
\end{tabular}

Table 3. Default parameters of simulation runs.

\begin{tabular}{|l|l|}
\hline Problem Solving Time (simulation ticks/bit): & $\mathrm{A}=1, \mathrm{~B}=2, \mathrm{C}=3, \mathrm{D}=4, \mathrm{CEO}=1$ \\
\hline Ratio of Memory Negligence (between 0 and 1$)$ & $\mathrm{A}=0.3, \mathrm{~B}=0.2, \mathrm{C}=0.1, \mathrm{D}=0, \mathrm{CEO}=0.3$ \\
\hline Transfer Time between Agents (simulation ticks) & 2 (constant for all activities) \\
\hline Simulation Run Time (ticks) & $8,000,000$ \\
\hline Action Preference Step-size Parameter $(\beta)$ & 0.2 \\
\hline Reward Step-size Parameter $(\alpha)$ & 0.1 \\
\hline
\end{tabular}




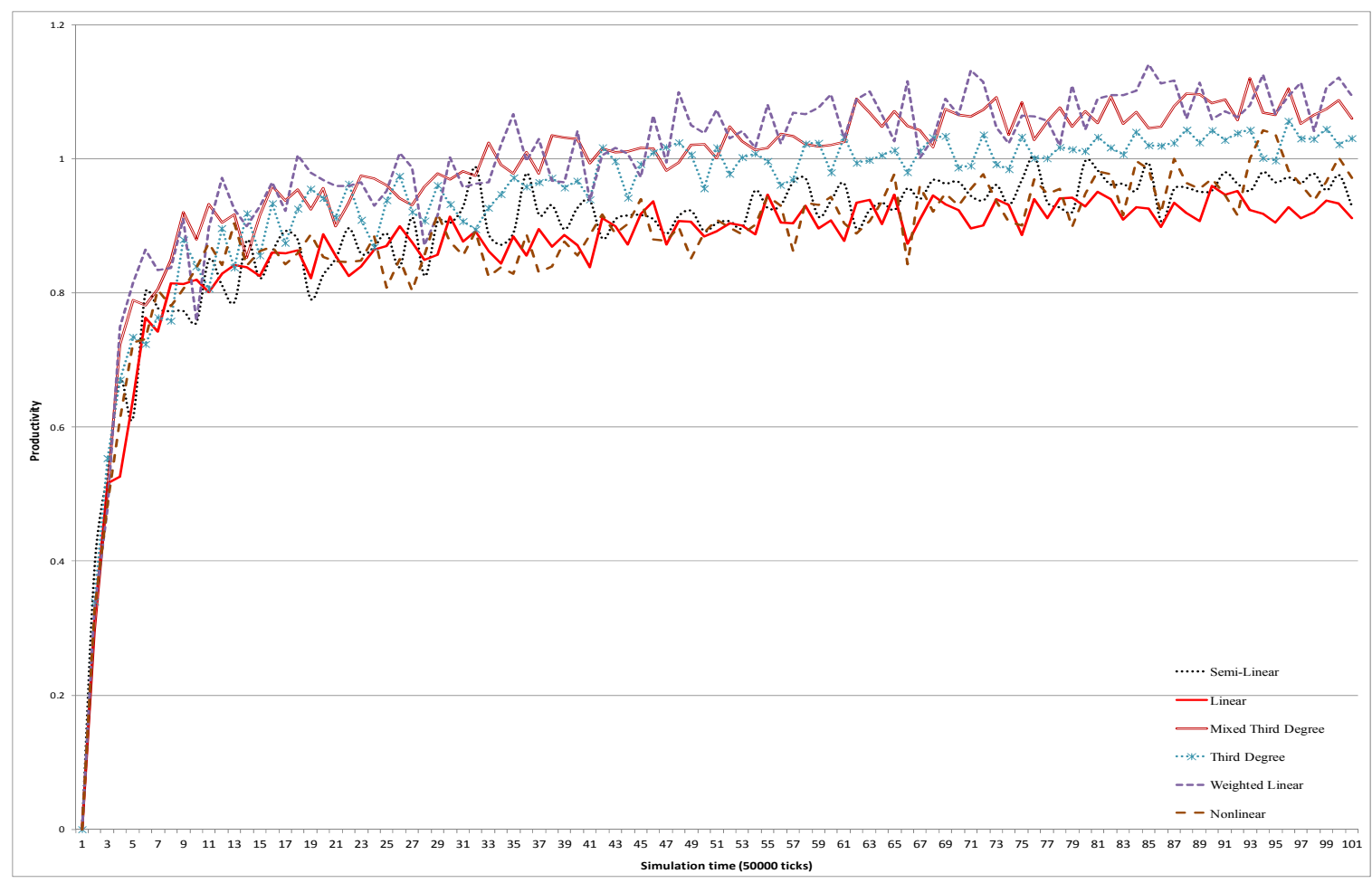

Figure 2. Comparison of the productivity level for different decision rules.

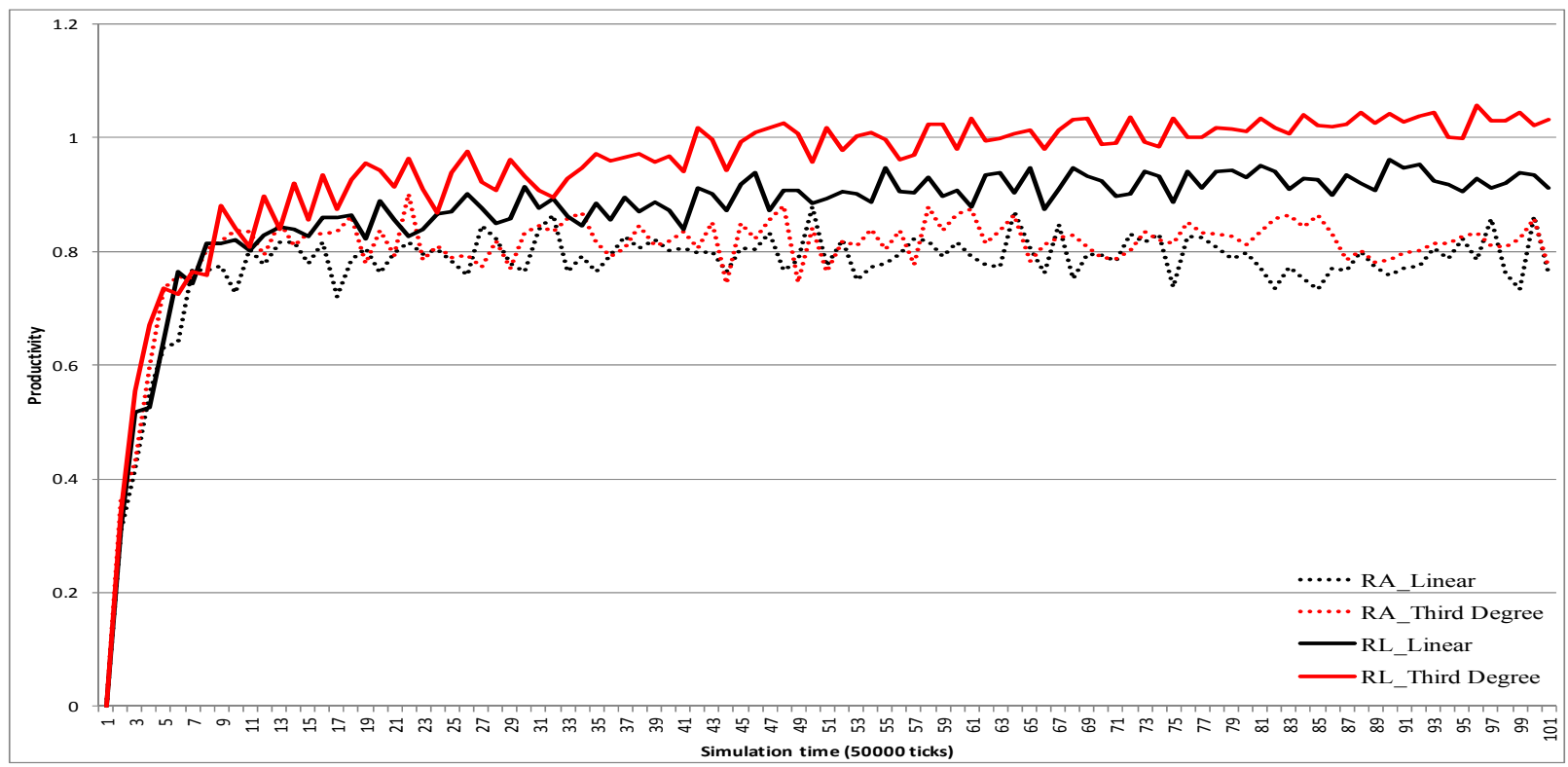

Figure 3. Comparison of productivity levels with Linear and Third Degree rules.

Table 4. Specifications of different decision rules.

\begin{tabular}{|l|c|c|c|}
\hline Decision rules & Entropy & Lower cut-off & Upper cut-off \\
\hline Linear: $Y=\sum_{\mathrm{i}=0}^{6} \mathrm{X}_{\mathrm{i}}$ & 3.1564 & 13 & 15 \\
\hline Semi-Linear: $\mathrm{Y}=\mathrm{X}_{0}+\mathrm{X}_{1} \mathrm{X}_{2}+\mathrm{X}_{3} \mathrm{X}_{4}+\mathrm{X}_{5} \mathrm{X}_{6}$ & 4.0932 & 12 & 16 \\
\hline Nonlinear: $\mathrm{Y}=\prod_{\mathrm{i}=0}^{6} \mathrm{X}_{\mathrm{i}}$ & 3.1564 & 36 & 108 \\
\hline Third Degree: $\mathrm{Y}=\mathrm{X}_{0}+\mathrm{X}_{1} \mathrm{X}_{2} \mathrm{X}_{3}+\mathrm{X}_{4} \mathrm{X}_{5} \mathrm{X}_{6}$ & 4.9667 & 13 & 21 \\
\hline Mixed Third Degree: $\mathrm{Y}=\mathrm{X}_{0}+\mathrm{X}_{1}+\mathrm{X}_{2} \mathrm{X}_{3}+\mathrm{X}_{4} \mathrm{X}_{5} \mathrm{X}_{6}$ & 4.5889 & 12 & 17 \\
\hline Weighted Linear: $\mathrm{Y}=\mathrm{X}_{0}+2 \mathrm{X}_{1}+2 \mathrm{X}_{2}+3 \mathrm{X}_{3}+4 \mathrm{X}_{4}+3 \mathrm{X}_{5}+2 \mathrm{X}_{6}$ & 4.5256 & 31 & 36 \\
\hline
\end{tabular}




\section{RESULTS AND DISCUSSIONS}

There are two sources of complexity in the model: environment's requirements complexity representing the environment intricacy and time complexity modeling the internal complexity of the organization. Only external complexity is discussed in this research.

To examine the effects of complexity, organization is exposed to different levels of environmental complexity, represented as decision rules. Environment's requirements complexity has some counterintuitive effects on the productivity. As seen in Figure 2, there exists a productivity gap between less complex solutions like Linear, Semi-Linear, and Nonlinear decision rules at the one hand and more complex decision rules such as Weighted Linear or Third Degree on the other hand. Discovering the cause of this pattern is complicated but the reason may be that when a less complex decision rule (with less entropy) is applied, solution space of the decision rule is smaller or put another way the difference among the frequency of solutions rule becomes greater according to Shannon (2001) and thus organization should be more accurate in predicting these values. In other words, less complexity/randomness of the decision rules means less variation in the search space and thus finding correct answers require more prediction power. However, the knowledge level gained by organization is bounded to agents' capabilities and consequently it has limited capabilities in targeting correct answers. In fact, since agents' learning in this model is incomplete there is always a degree of error. As a result, CEO's prediction accuracy is limited. That is why organization has poorer performance with less complex decision rules, contrary to the intuitive expectation. Likewise, when the entropy of a decision rule rises, the range of decision rule is more than before (i.e. search space is bigger) and it is more probable for $C E O$ to hit the targets, considering its learning errors. The comparison of RL performance versus Random-Action for various decision rules reveals that there is an interaction between CEO leadership defined as RL in this research and the environmental complexity. Figure 3 depicts an example where Linear as the least complex and Third Degree as the most complex decision rules are compared. The difference between RL and Random-Action algorithm, where $C E O$ randomly changes agents among roles is less with Linear rule in comparison to that of Third Degree rule. It means that RL algorithm performs more efficiently with more complex problems. The same trend is seen for Mixed Third Degree and Semi-Linear rules (See Figure 4). These results highlight the importance of leadership in complex environments. When the environment is more complex, intelligent behaviors of managers (here modeled as $\mathrm{RL})$ can be more productive for organizations.

\section{CONCLUSIONS}

In this paper, an agent-based model is presented by which the effects of the environmental complexity on organizational performance are investigated. The developed model is capable of modeling the dynamics of environmental complexity on organizational productivity, something missing in the prevalent empirical studies in this area. It has been found that organization takes advantage of complexity to improve its productivity. It seems that more complex environments as defined in this research offer possibilities to organization to learn more appropriately in that the search space is bigger and predictive accuracy of learning is less critical. The computational model developed provide new opportunities for doing research about learning memory of organizations and internal complexity of organzations. 


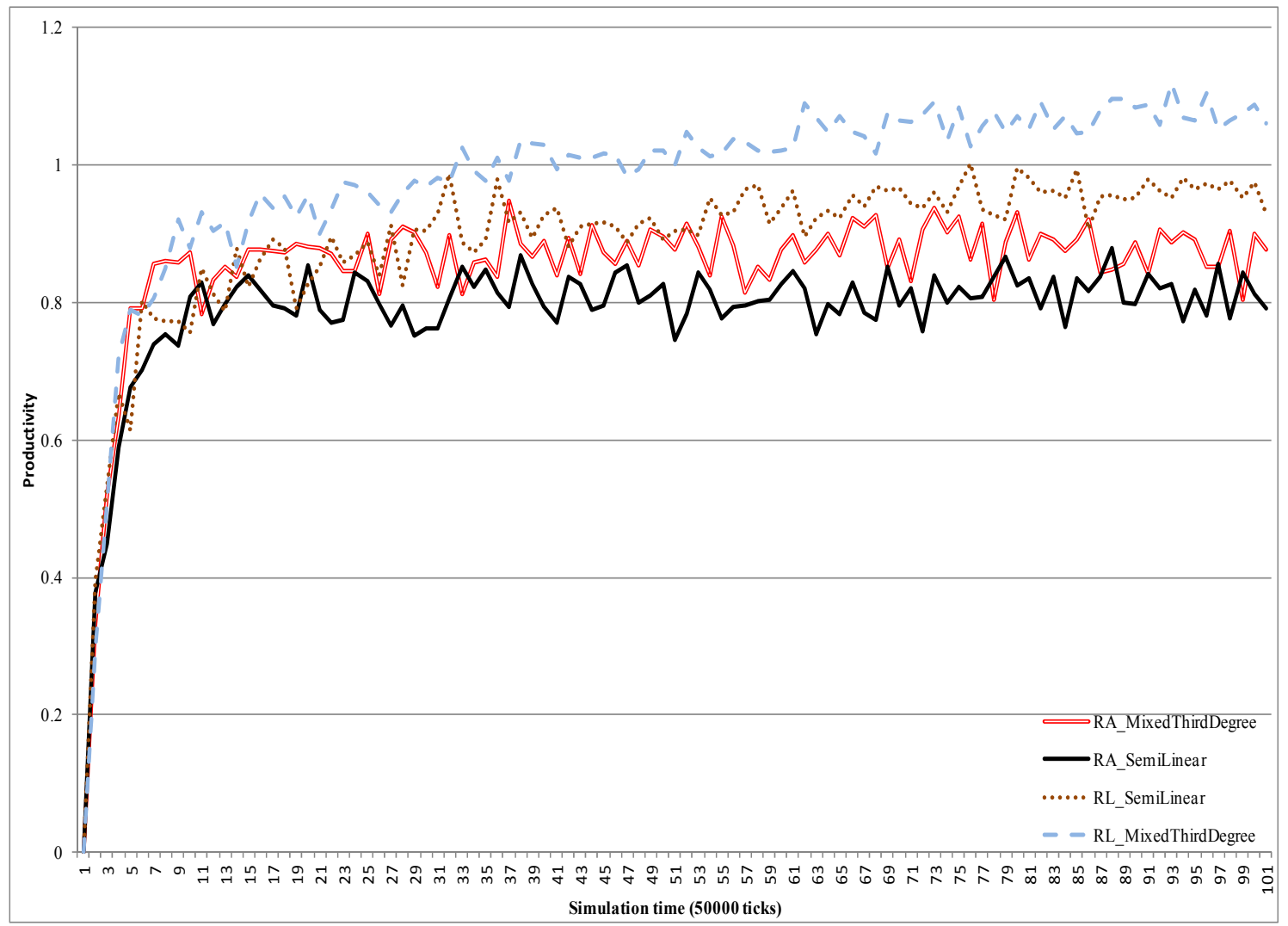

Figure 4. Comparison of productivity levels with Mixed Third Degree and Semi-Linear rules.

\section{REFERENCES}

Carley, K. M. (2000). Organizational adaptation in volatile environments Computational Modeling of Behavior in Organizations. Ilgen and Hulin. Washington, D.C., American Psychological Association.

Cyert, R. M. and J. G. March (1963). A behavioral theory of the firm. Englewood Cliffs, N.J. :, PrenticeHall.

Galbraith, J. R. (1973). Designing complex organizations.

Godwyn, M. and J. H. Gittell, Eds. (2012). Sociology of organizations: structures and relationships Thousand Oaks, Calif., Sage/Pine Forge Press.

Lin, Z. and K. M. Carley (2003). Designing stress resistant organizations : computational theorizing and crisis applications. Boston :, Kluwer Academic Publishers.

March, J. G. (2008). Explorations in organizations Stanford, Calif., Stanford Business Books.

Sastry, M. A. (1997). "Problems and paradoxes in a model of punctuated organizational change." Administrative Science Quarterly: 237-275.

Scott, W. R. (1998). Organizations: rational, natural, and open systems. Upper Saddle River, NJ, Prentice Hall.

Shannon, C. E. (2001). "A mathematical theory of communication." SIGMOBILE Mob. Comput. Commun. Rev. 5(1): 3-55.

Siggelkow, N. and J. W. Rivkin (2005). "Speed and Search: Designing Organizations for Turbulence and Complexity." Organization Science 16(2): 101-122.

Simon , H. A. (1996). The sciences of the artificial Cambridge, Mass., MIT Press.

Simon, H. A. (1997). Administrative behavior: a study of decision-making processes in administrative organizations. New York, Free Press. 